\title{
Apresentação: da teoria das abstrações à crítica chasiniana de Lukács
}

Vânia Noeli Ferreira de Assunção*

O excerto que se oferece para o deleite do leitor é parte de um texto com história curiosa. Em 1995, tendo decidido pela publicação do livro Pensando com Marx, de Francisco J. S. Teixeira, J. Chasin, então editor da Editora Ensaio, começou a escrever um posfácio cujo objetivo era salientar as principais qualidades do texto de Teixeira, destacadamente, o fato de fazer uma leitura imanente do texto marxiano. Nesse mister, Chasin contrapôs o acertado procedimento de Teixeira à atitude prevalente de ler Marx por lentes que o distorcem, atribuindo-Ihe elementos que lhe são exteriores. Chasin quis exemplificar algumas dessas interpretações deturpadas e lhes fazer a devida crítica, o que, por outro lado, demandou dar a conhecer em detalhes o procedimento marxiano - que já havia décadas buscava redescobrir pela análise acurada e sem imputações dos seus próprios textos, estudados detalhadamente em monografias que avaliavam o conteúdo e as transformações pelas quais passou o ideário marxiano em seu período formativo. E assim, ao fim e ao cabo, o tal posfácio acabou ganhando um corpo não planejado no início, tornando-se um calhamaço de mais de 200 páginas de um debate tão denso que se descolou do livro original com o qual veio a lume.

Dividido em cinco tópicos, além de uma breve introdução, o texto de Chasin intitulado Marx. estatuto ontológico e resolução metodológica ${ }^{1}$ - toma como mote o longevo debate epistêmico em torno do "método marxiano" para ensejar uma profunda reflexão filosófica sobre o pensamento do teórico alemão e as querelas gnosiológicas em que foi envolvido. Numa breve introdução, ele apresenta o tema, salientando como fundamental a necessidade de "reproduzir pelo interior mesmo da reflexão marxiana o trançado determinativo de seus escritos", frisando que "antes de

\footnotetext{
* Professora da Universidade Federal Fluminense - Rio das Ostras. Coeditora da Verinotio. E-mail. vanianoeli@uol.com.br.

1 CHASIN, J. Marx. estatuto ontológico e resolução metodológica. São Paulo: Boitempo, 2009. Originalmente publicado como "Posfácio" a: TEIXEIRA, F. J. S. Pensando com Marx. São Paulo: Ensaio, 1995.
} 
interpretar ou criticar é incontornavelmente necessário compreender e fazer prova de haver compreendido". Expõe, em outros termos, os elementos mais gerais de uma análise imanente assentada no reconhecimento do objeto em exame - a formação ideal - em sua objetividade e autonomia em relação ao sujeito que investiga; e mostra como tal postura está na contracorrente do monopólio interpretativo gnosioepistêmico do pensamento de Marx.

No item Crítica do amálgama originário, Chasin situa o debate em torno da originalidade do ideário marxiano, cujas origens são comumente remetidas à apropriação seletiva e mesclada de três partes do que de melhor haveria no pensamento europeu de então - a teoria política (ou o socialismo, em outras versões) francesa, a filosofia alemã e a economia política inglesa -, mistura à qual teria agregado finalmente o seu método específico. Segundo tal interpretação, portanto, no processo de constituição de seu pensamento próprio, Marx teria forjado uma "aglutinação eclética" de conteúdos dos corpos teóricos então existentes e lhes aditado uma resolução epistêmica peculiar: o uso da dialética enquanto uma sorte de método universal de investigação. A transformação da dialética em método e a redução da contribuição marxiana à capacidade de agregar partes de teorias e procedimentos já existentes são, segundo Chasin, equívocos que levam à perda dos nódulos centrais e da inédita novidade do pensamento marxiano.

O terceiro item do texto, bem mais encorpado, chama-se Gênese e crítica ontológica. Ali, Chasin critica a noção vulgarmente disseminada sobre a origem e as "fontes" do pensamento marxiano, sustentando a impossibilidade da operação necessariamente eclética de repicar, peneirar e embaralhar componentes de três campos filosóficos bastante distintos entre si num novo discurso minimamente rigoroso e articulado. Seguindo caminho oposto ao da imputação, realiza um rigoroso estudo, mantendo uma "submissão ativa aos escritos investigados", dos textos de Marx do período 1841-43 - ao cabo do qual não encontra vestígios do pretendido amálgama originário. Guiando-nos pelo percurso formativo do jovem Marx, o teórico paulistano chega a uma conclusão radicalmente diferente: à luz de problemas materiais específicos para os quais neles não encontrou respostas adequadas - e sob forte influência feuerbachiana no tocante à crítica a Hegel -, Marx confrontou os três pontos altos do pensamento europeu de sua época tendo sempre em mente a presença das realidades específicas às quais estavam ligados por liames complexos e incontornáveis, submetendo-os a uma crítica radical. Criticando o que havia de melhor na produção 
do período em termos de prática política, filosofia e ciência, o teórico alemão concluiu pela sua falibilidade imanente para apropriar-se idealmente do mundo atual, inaptidão que não era, portanto, metodológica, mas ontológica: trata-se do esgotamento de todo o patamar anterior de racionalidade e atividade que estava dado, extenuação que tem raízes nos próprios complexos reais em transformação, os quais eram sempre perspectivados na efetivação daquela crítica. Daí que, a partir de 1844, quando paulatinamente constituiu seu pensamento próprio, de forma simultânea à crítica demolidora das teorias de sua época, este representasse uma visão global de mundo totalmente nova, inédita, uma viragem radical em relação a toda prática e à teoria anterior (a sua, pessoal, e a da tradição), situando-se muito além delas.

O terceiro item do texto de Chasin, do qual falaremos com um pouco mais vagar, chama-se A resolução metodológica e se inicia com uma saudável provocação: se entendido nos moldes tradicionais, não há um método em Marx. Mais ainda: tal ausência não se deve a negligência ou lapso, mas deriva de uma afirmação de ordem teórico-estrutural não convencional, assentada sobre duas estacas: a fundamentação ontoprática do conhecimento, de um lado, e a determinação social do pensamento e presença histórica do objeto, doutro, intimamente relacionadas à teoria das abstrações que Chasin descobre em Marx e à lógica da concreção, que é propriamente o procedimento de pesquisa marxiano. Sempre acompanhando minudentemente os escritos do Mouro, Chasin demonstra que os pressupostos ontológicos do pensamento daquele o impediram de tomar o problema do conhecimento como exercício de uma subjetividade autônoma, de maneira que o alemão acabou reconfigurando a questão de forma completa e radical, finalmente situando-a em seu lugar e termos próprios, isto é, no âmbito global do complexo humano-societário.

Como lembra Chasin, a especificidade da objetividade social, objeto de estudo de Marx, é ser um complexo categorial que reúne sujeito e objeto sob o eixo da atividade sensível, é objetividade subjetivada ou subjetividade objetivada. Dito de outra maneira, a objetividade e a subjetividade humanas são autopostas, num processo infinito e contraditório que tem na atividade sensível - a própria produção da vida - o seu momento determinante. $\mathrm{Na}$ realização do trabalho, particularmente, o conhecimento é indecomponível da atividade; a teleologia - o pôr, consciente, de objetivos - é justamente o momento ideal que antecede e guia a efetivação da ação. Como salienta Chasin, a prática pressupõe ao menos dois momentos fundamentais: a subjetividade proponente (a teleologia) e a subjetividade receptora (a capacidade 
cognitiva que possibilita a inteligibilidade da malha causal efetiva, que deve ser respeitada como condição de sucesso da empreitada). Esta conjunção cognitiva entre sujeito e objeto se espraia do trabalho para todas as outras formas de práxis social, com os pertinentes distintivos entre elas. Dessa maneira, em vez de erigir-se sobre as movediças bases de um debate acerca da possibilidade do conhecimento, necessariamente subjetivas, Marx firmou-se em pressupostos reais, repondo a questão da possibilidade do saber na esfera ontoprática da sociabilidade, enquanto resultado da atuação prática e teórica do homem, ser social, quer dizer, do caráter produzido do mundo sensível e da certeza sensível.

$\mathrm{Na}$ descoberta desse enlace - ou melhor, dessa transitividade contínua - entre sujeito (ativo) e objeto (mutável) está o segredo do procedimento marxiano, de talhe ontológico, que nunca separa as dimensões inseparáveis do ser social, e, portanto, não opõe ser e pensar, intrinsecamente cosidos no âmbito da sociabilidade (mas nunca confundidos, como na especulação). Chasin sintetiza tal debate sob o qualificativo fundamentação ontoprática do conhecimento, isto é, o reconhecimento de que este é determinado pela gênese e necessidade social que o engendram: todo saber supõe um ser que pensa, este ser é social e, portanto, seu pensamento também o é. Dessa forma, não faz sentido um debate escolástico, meramente epistemológico, sobre o conhecimento como uma suposta atividade autônoma de uma razão sem corpo.

O tema está também correlacionado a outro, da determinação social do pensamento e presença histórica do objeto, como Chasin o sintetiza, frisando outra vez o nexo fundamental entre consciência (formação ideal) e sociabilidade. Sem jamais reduzi-las a mero epifenômeno ou reflexo mecânico da sociabilidade, Marx mostrou que as formas de pensamento estão enraizadas na realidade histórica de que advêm e são suas expressões conscientes, sejam reais ou ilusórias: atividade ideal é atividade social. Tendo nascido de uma determinada necessidade e para atender a dados objetivos, todo conhecimento é, desde logo, interessado. O filósofo paulistano mostra aqui como a abordagem gnosioepistêmica sobre o pensamento - em particular, no debate sobre a ideologia - passa ao largo da descoberta de Marx. Não há contradição entre interesse e conhecimento, nem associação direta entre conhecimento com funções sociais e falsificação, de vez que o saber é sempre intencionado, tanto o verdadeiro quanto o falso, sendo necessário perscrutá-lo para averiguar sua gênese, sua função social e sua (in)coerência e (in)coesão. 
Chasin realça ainda outra conquista teórica marxiana: a da percepção da sociabilidade como fonte primária, ou melhor, como condição de possibilidade do pensamento, tanto no sentido de fornecer-lhe as condições mais adequadas quanto no de obstar seu desenvolvimento. Condições sociais específicas podem favorecer ou embaraçar o exercício apropriado da cientificidade ou da reflexão em duas direções: pelo grau de desenvolvimento do objeto ou pela posição do sujeito que busca o conhecimento. O processo de conhecimento é relacional, multilateral, não se situando apenas no sujeito (pois todo saber versa sobre algo) ou no objeto (cuja existência por si é apreensível por um sujeito ativo). Assim, de um lado, a plena estruturação categorial de um objeto exerce papel impulsionador na relação cognitiva, enquanto um caráter germinal ou um desenvolvimento incompleto a empata ou dificulta: a compreensão do objeto já posto em sua complexidade propicia chaves para a compreensão (sempre com base no destaque da diferença específica) do objeto menos desenvolvido. De outro lado, a posição objetiva do pesquisador em dado tempo e lugar históricos - o lócus social em que está situado - pode predispor ou obstar a cognição da realidade material ou espiritual. Em poucas palavras, a objetividade científica decorre de uma confluência entre um sujeito ativo situado em posição adequada à cientificidade e um objeto amadurecido suficientemente para possibilitar sua apreensão.

Explicitados os seus pressupostos fundamentais, resta pormenorizar o procedimento de Marx. Este detalhamento está dado na teoria da abstração, outra importante descoberta que Chasin realiza no exame minucioso da produção marxiana, teoria consistente e de grande importância, inobstante seu caráter fragmentário. 0 pensador alemão já havia enfatizado que nos estudos sobre a sociabilidade não são empregáveis instrumentos e métodos experimentais semelhantes aos das ciências da natureza, dado que se trata de objetos totalmente distintos. Em substituição a estes, - principal instrumento para a reprodução intelectual de entidades reais na esfera social é a força de abstração, a competência intelectiva de esquadrinhar as coisas de uma forma adequada tanto à natureza dos objetos quanto à do próprio sujeito envolvidos na relação cognitiva. Partindo da destilação de abstrações razoáveis, segundo Chasin, o método marxiano nada mais é do que o modo de produção (processo em que o objeto tem a prioridade e exerce a regência) de concretos pensados, para o qual é fundamental o enfrentamento do objeto sensível em sua integralidade e sem nenhuma mediação metodológica previamente estabelecida. 
As abstrações, categorias simples que estão dadas tanto na realidade efetiva quanto no pensamento, têm razoabilidade quando correspondentes aos objetos que representam. Elas fixam e salientam aspectos reais, frequentemente isolados, comuns a diferentes épocas, dos complexos fenomênicos em análise e, embora não determinem nenhum objeto real - donde, serem abstrações -, são indispensáveis, já que sem elas não seria possível conceber nenhuma formação real. Contudo, estas abstrações ainda não são o conhecimento real, mas "uma representação caótica do todo", uma vez que estão vazias e desordenadas: segundo Marx, são apenas o ponto de partida do método cientificamente exato, a partir do qual se faz a viagem de volta ao concreto. Em tal rota, é preciso um trabalho das abstrações, um processo de síntese que proceda à intensificação ontológica daquelas abstrações isoladoras, aproximandoas e comparando-as aos traços efetivos dos objetos estudados - pelos quais a compreensão será parametrada. Com outro passo, a delimitação, as leis gerais vão perdendo força em prol da particularização e da singularização da fisionomia das abstrações, que se tornam mais bem delimitadas, determinadas histórica e socialmente. Outro momento do trabalho das abstrações descoberto por Chasin em Marx é a articulação, a remissão à multilateralidade ou complexidade em que se situa toda conformação fenomênica, pela qual se explicita a conexão íntima das categorias em pauta, abordando suas determinações reflexivas recíprocas, ou seja, os pares ou conjuntos de categorias que têm íntima (e contraditória) conexão entre si. Para não incorrer em homogeneização irreal, é necessário explicitar as proporções e as qualidades com que interagem - e neste mister destacar o momento preponderante, aquela categoria que, pelo seu peso específico, é estruturante da relação.

Pela descrição dos atos operativos fica evidenciado que a ordem e a sequência em que aparecem os elementos e os lugares por eles ocupados estão subordinadas ao composto ontológico do objeto estudado, não a uma legalidade autônoma, reproduzindo no concreto pensado o ordenamento intrínseco ao objeto em pauta. Com este procedimento - o da retilínea constatação de efetividades -, Marx revelava, conforme Chasin, a própria lógica das coisas, seus elementos constituintes e sua teia de determinações e relações multiformes, sua dialeticidade imanente. É por isso que a operacionalidade acima arrolada reveladoramente enuncia a universalidade dos processos, mas sem detalhar nenhum ato em particular, pois estes só poderão ser efetivados na analítica específica dos objetos, para a qual não há mapas nem roteiros prévios. 
A parte do texto que ora se está publicando, Da teoria das abstrações à crítica de Lukács, é ainda mais densa. Não nos deteremos nela a não ser o estritamente necessário para situar o leitor sobre o material que poderá avaliar por si mesmo. Nesse item, Chasin faz a reconstrução detalhada e analítica de grandes trechos de Introdução a uma estética marxista (1956) e da Estética (1962) de Lukács, objetivando trazer à tona alguns elementos de seu pensamento que considera problemáticos. De acordo com o filósofo brasileiro, num percurso que acompanha cuidadosamente, Lukács, intentando, num primeiro momento, discutir a questão da particularidade no campo da estética, acabou tomando um caminho que o levou à constituição de uma lei histórica universal, encarnada na dialética do trânsito entre universal, particular e singular. Ademais, acabou vendo Hegel de forma muito positiva - os formalismos ou logicismos teriam permanecido nele apenas como parte das formulações débeis ou errôneas, não nos acertos - e, aproximando-o por demais de Marx, viu seu logicismo como a base para o próprio método marxiano.

Tendo em vista o teor dos comentários críticos desenvolvidos nessa parte do escrito, é imperioso enfatizar que estes estão voltados exclusivamente a um problema específico, que diz respeito às relações entre Marx e Hegel. É deveras conhecido o aspecto crucial desta questão, que ainda hoje assedia os intérpretes do legado marxiano - e que não escapa ao olhar atento de Chasin, preocupado com as tendências que aproximam demasiadamente um autor de outro, sobretudo no que diz respeito às questões de ordem metodológica. Nesse sentido, ainda que nas páginas de Para uma ontologia do ser social e de seus Prolegômenos seja possível constatar um esforço importante de Lukács para se desvencilhar da presença da "lógica dialética", tal problema continuou a assombrar o seu legado filosófico e merece tratamento cuidadoso. Chasin, sem dúvida, oferece contribuição fundamental também nesse campo, sobretudo porque Introdução a uma estética marxista, publicado no Brasil já em 1978, pela Civilização Brasileira, rapidamente ganhou adeptos convictos de que ali se tratava de fato de uma introdução ao pensamento estético do autor e, ademais, de uma configuração acertada do procedimento metodológico de Marx e do próprio Lukács, percepção que, infelizmente, prossegue até hoje em bolsões de não especialistas. $^{2}$

\footnotetext{
${ }^{2} \mathrm{O}$ próprio Chasin, em certo momento de seu processo de aproximação à obra de Lukács, escreveu um
} artigo intitulado Lukács: vivência e reflexão da particularidade (Nova Escrita Ensaio, n. 9, São Paulo, 
Em sua investigação, Chasin reconstitui a análise lukácsiana da questão da universalidade e da particularidade. Lukács expôs a forma como a história da filosofia tratou a questão (em geral, enfatizando uma das categorias e negando a outra), detendo-se na abordagem hegeliana, por ele elogiada: ao pôr a dialética universal/particular/singular no centro da lógica, Hegel teria conseguido, a despeito do seu idealismo, reproduzir filosoficamente a realidade histórico-social. Tal dialética histórica, apesar de seu tratamento abstrato em Hegel, seria uma lógica de novo tipo, tendencialmente correspondente à realidade viva. Aqui, segundo Chasin, a crítica de Marx ao logicismo e à especulação hegelianos é secundarizada - e, portanto, o salto do pensamento marxiano é minimizado. O teórico paulistano, por meio da reconstituição do texto de Lukács, principalmente daquele publicado originalmente em 1956, mostra como, na abordagem da particularidade, o discurso vai ganhando foro de problema universal (não mais afeito à estética, como inicialmente pensado). De acordo com Chasin, o filósofo húngaro não encontrou amparo, senão de modo esparso e mal alinhavado, nos escritos marxianos, de forma que as remissões ao filósofo alemão foram rareando conforme o tratamento do tema ia sendo logicizado. O que torna a questão ainda mais problemática é o fato de o húngaro ter afirmado se especar em Marx, quando se tratava de uma reflexão dele próprio.

Tencionando estabelecer um vínculo lógico entre Marx e Hegel, Lukács afirmava que no capítulo I de $O$ capital haveria uma construção lógica, uma apropriação particular do método hegeliano que marcaria a cientificidade marxiana - e não só não encontrou arrimo nos textos de Marx para assegurar sua asserção como ignorou diversas manifestações do teórico alemão acerca da diferença e inclusive da oposição entre o seu método e o de Hegel. O filósofo húngaro, conforme Chasin, não atentou para a diferença entre o método de pesquisa - que tem a prioridade no procedimento marxiano e que este reputou como o exato oposto do método de Hegel - e as "formas de tratamento", ou seja, o método de exposição, momento em que "coqueteou" com aquele. Lukács equiparou as três formas do valor analisadas por Marx a momentos históricos que encarnariam alternadamente singularidade, particularidade e universalidade, equiparando método histórico a método lógico, ou seja, a indistinção entre análise e exposição o levou a correlacionar a realidade econômica global a uma

Escrita, 1982) no qual ressaltava a importância da categoria na vida e na obra do autor. Nesse sentido, o "Posfácio" ganha ares de acerto de contas também com a própria trajetória. 
silogística. Dessa maneira, no entender de Chasin, Lukács retomou os problemas analisados por Marx sob uma ótica que este havia criticado e superado, quer dizer, fez retroagir a questão do plano ontológico em que o alemão a situou para o da teoria do conhecimento. Ademais, não percebeu que, se há vínculos com Hegel - pensador de alta estatura, não poderia ser meramente ignorado -, as contribuições deste para o pensamento marxiano são secundárias e foram assimiladas a partir de uma ruptura abissal: afinal, a crítica radical à especulação havia sido feita por Marx ainda nos primeiros anos da década de 1840. 0 autor de $O$ capital reconheceu o pioneirismo de Hegel na exposição das formas gerais do movimento, em que era possível encontrar um núcleo racional, mas denunciando, ao mesmo tempo, seu caráter abstrato, o qual, eliminando os aspectos distintivos dos diversos movimentos, chegava ao movimento em estado abstrato, ao movimento puramente formal. Por sua vez, a dialeticidade exposta no pensamento marxiano é o movimento histórico das próprias categorias enquanto formas de ser reproduzidas pelo concreto pensado, e dessa maneira dialética se descobre, mas nunca se aplica.

Mesmo na Estética, obra que, conforme Chasin, não repete as débeis construções teóricas da Introdução a uma estética marxista quando retoma a questão da particularidade, Lukács acabou incorrendo em erro semelhante ao debater o em-si hegeliano. Marx teria, para Lukács, apropriado o método de Hegel, que valoriza a abstratividade, que tem uma noção vazia como alicerce. Chasin mostra como, por muitos meandros que o leitor terá condição de verificar, Lukács chegou a uma noção de em-si como uma figura epistemológica, na qual a abstratividade - a pobreza do concreto epistemológico - é o garante do acesso à realidade e da distinção entre objetividade e subjetividade. Bem assim, Chasin avalia que a categoria da totalidade é entendida por Lukács, em boa parte de sua tematização, como um postulado da teoria do conhecimento (como ponto de vista, ou seja, uma configuração da subjetividade, enquanto em Marx se trata da formação real e concreta, complexa e contraditória, que, reproduzida pelo pensamento, torna-se concreto pensado). E, por fim, aprisionado nas malhas da lógica universal/particular/singular, Lukács acercou-se da problemática da particularidade sem atinar para o caráter primordial do processo de particularização (determinação ou concreção, conforme exposto na teoria das abstrações) no procedimento marxiano do caminho de volta das abstrações razoáveis ao concreto em sua complexidade e articulação.

Por fim, no item final do livro cujo excerto ora se apresenta - A analítica das 
coisas -, Chasin reconstitui diversos momentos do pensamento marxiano, desde os Manuscritos de 1844 até as Glosas a Wagner (1880), para demonstrar a constituição da teoria das abstrações na sua origem e mostrar como os delineamentos desta estão presentes durante toda a sua produção intelectual adulta. A teoria das abstrações, frise-se, está centrada na prioridade e regência do objeto. Nessa subsunção aos objetos, os procedimentos analíticos marxianos não assumem o feito formal e prévio de roteiro metodológico, mas a configuração abstrata dos passos necessários à apropriação ideal das coisas - quer dizer, a irresolução analítica das figuras da teoria das abstrações - é a outra face da analítica das coisas, ou seja, a pesquisa é a busca pela lógica específica do objeto específico, está radicada e subordinada à "terrenalidade das coisas e dos homens concretos".

Para finalizar esta Apresentação, façamos uma breve síntese da crítica chasiniana. Por desconhecer a teoria das abstrações e o detalhamento do procedimento marxiano de pesquisa, Lukács não pôde falar deste senão no plano mais geral (dos princípios e grandes condicionamentos históricos), sem referência a seus procedimentos analíticos; ignorou, nesse imbróglio, a forma específica de a "cabeça pensante" se apropriar do mundo (e, assim, só pôde tratar dos limites sócio-históricos à apreensão de certas categorias, olvidando a posição do sujeito cognoscente), tornou a dialética universalidade/particularidade/singularidade uma sorte de método universal, aproximou em demasia Marx de Hegel, logicizou o procedimento marxiano e desconsiderou em vários momentos o ineditismo da posição marxiana, que é de porte ontológico, como ele próprio veio a revelar em textos fundamentais como Para uma ontologia do ser social, influenciadora inclusive do próprio texto de Chasin.

Conforme conclui o teórico paulistano, o filósofo húngaro - na sua longa e tortuosa jornada intelectual rumo à apreensão correta do pensamento marxiano, que teve diversas fases, nunca se completou e conheceu problemas até o fim (Lukács não atinou com a teoria das abstrações nem na Ontologia) - construiu um edifício conceitual em que diferentes critérios se esbatiam. Chasin frisa, contudo, que essas debilidades não representam todo o pensamento de Lukács e que a própria crítica a que os submete é ela mesma inspirada por ele - cujo mérito de ter assinalado (ainda que tardiamente) o caráter ontológico e advertido para outras contribuições de Marx, além da própria inclinação para a ontologia, singularizam-no no panteão dos pensadores marxistas. Inobstante tais conquistas, Lukács não chegou a compreender na sua integralidade a teoria das abstrações nem atentou para sua cosedura, muito 
embora tenha percebido seus elementos conceituais mais relevantes, que, contudo, foram por ele engastados em uma estrutura estranha ao próprio corpo teórico marxiano. Em síntese, dada a estatura do pensamento lukácsiano, Chasin considera fundamental submetê-lo a análise e, sob os parâmetros da produção marxiana, apartar as imensas contribuições dos desacertos e imprecisões. E, lembra ainda o filósofo paulistano, os embaraços de Lukács são aparentados aos que perpassaram toda a história da ontologia, atravessada sempre por questões gnosioepistêmicas: é a paradoxal dificuldade de se apropriar idealmente do mundo em que se vive.

\section{Como citar:}

ASSUNÇÃO, Vânia Noeli Ferreira de. Apresentação: da teoria das abstrações à crítica chasiniana de Lukács. Verinotio, Rio das Ostras, v. 27, n. 1, pp. 146-156, jan./jun 2021. 